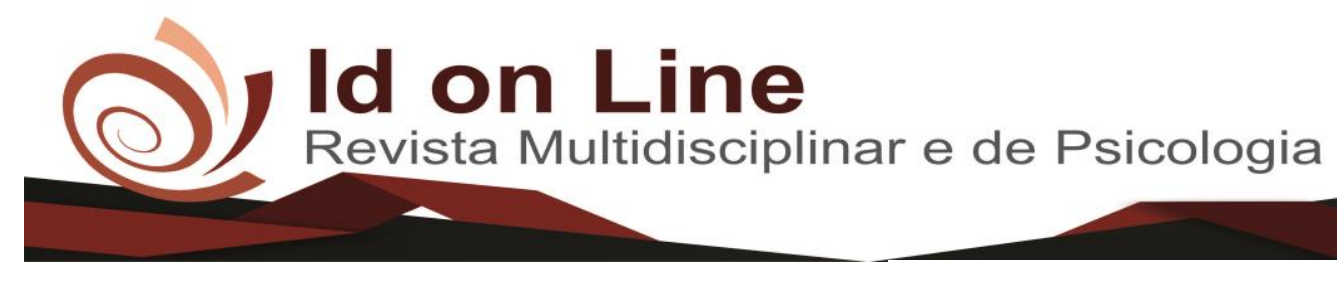

DOI: 10.14295/idonline.v13i46.1931

Comment

\title{
O Lúdico na Educação Infantil
}

\author{
Josilene de Resende Santos ${ }^{1}$; Joelson Rodrigues Miguel $^{2}$
}

\begin{abstract}
Resumo: Este trabalho tem como objetivo conhecer as possíveis lacunas no desenvolvimento de atividades Lúdicas na Educação Infantil na cidade de Ribeirópolis/ Sergipe, diante da importância do lúdico na produção do desenvolvimento na educação infantil. Enfatiza-se a necessidade de resgatar a alegria de aprender com o prazer no ambiente escolar através de atividades prazerosas, nos primeiros contatos que a criança tem com o mundo da leitura e da escrita de forma sistematizada. A importância da ludicidade deve ser reconhecida, valorizada, implementada esporadicamente, superando os desafios, descobrindo a graça do mundo da leitura de forma espontânea, com emoção, dando a importância devida aos sonhos e cada criança que formula seu "mundo" através de brincadeiras.
\end{abstract}

Palavras-chave: Lúdico. Aprendizagem. Creches. Educação Infantil.

\section{The Playful in Early Childhood Education}

\begin{abstract}
The aim of this work is to know the possible gaps in the development of playful activities in Early Childhood Education in the city of Ribeirópolis / Sergipe, because of the importance of the playful in the production of the development Early Childhood Education. It should be noted the necessity of rescue the hapiness of learn with the pleasure in the school environment through pleasurable activities, in the first contact that the child has with the world of reading and writing in a systematic way. The importance of the playfulness must be recognized, valued, implemented sporadically, overcoming challenges, discovering the grace of the world of reading spontaneously, with emotion, giving due importance to dreams and every child who formulates his "world" through kidding.
\end{abstract}

Key-words- Playful. Learning. Daycare. Early Childhood Education.

\section{Introdução}

É na infância que surge a vontade de brincar. A brincadeira, a música, o brinquedo e os jogos trazem o mundo para a realidade infantil, desenvolvendo assim potencialidades e inúmeras habilidades. Nesse novo mundo a criança poderá imaginar, criar, recriar, associar e se descobrir.

\footnotetext{
${ }^{1}$ Graduação em Pedagogia pela Universidade Tiradentes, Brasil(. Professora do Colégio Paraíso Cultural , Brasil. Mestrado em Educação pela Flórida Chistian University.

${ }^{2}$ Docente na Universidade Federal de Campina Grande. Master in Arts - Musicologia - pela Universidade de Campbellsville KY, Doutorado em Ciências da Educação pela Universidade Autónoma de Asunción PY e Pós-Doutorando pela Florida Christian University, onde atua como tutor para Dissertações e Teses. Contato: joelsonrmiguel@ hotmail.com.
} 
Esta pesquisa intitulada O Lúdico na Educação Infantil, ressalta a importância das atividades lúdicas no processo de desenvolvimento e aprendizagem infantil. Suas aplicações pedagógicas têm sido defendidas constantemente por biólogos, psicólogos e pedagogos; para eles os jogos e brincadeiras podem ser usados não só para divertir, como ainda para instruir, informar e educar, aliando a liberdade experimental e emocional da atividade lúdica à precisão do pensamento abstrato.

O movimento, o jogo, a ação corporal e a vivência das sensações constituem o elo entre o eu, o mundo e os outros, este é o primeiro plano de ter um fazer mental e expressivo. Tal confirmação justifica o esforço para integrar o movimento às esferas educativas numa dimensão simultaneamente revolucionária e significativa.

Não se pode abordar de modo detalhado as situações pedagógicas que implicariam uma referência ao lúdico, mas acredita-se que diante das dúvidas que o docente tem em relação a este assunto, busca-se elucidar a seguinte problemática: A inópia do lúdico na educação infantil.

Ao brincar a criança se relaciona com outras crianças, sendo capaz de aprender a trabalhar individualmente e em grupo, se desenvolve física, psíquica e socialmente. Um brinquedo pode se transformar em ferramenta facilitadora para que a aprendizagem ocorra.

Esta pesquisa teve como objetivos discutir as atividades lúdicas na educação infantil, já que crianças e jovens buscam incessantemente novidades e desafios, demonstrando muitas vezes insatisfação e falta de persistência no que fazem. Não é difícil vê-los desistir frente aos obstáculos. Diante de tal realidade, a escola se desgasta ao insistir no modelo tradicional de ensino - aprendizagem, sem conseguir a atenção do educando. Assim, faz-se necessária uma prática pedagógica voltada para a utilização do lúdico como forma de trabalhar a concentração, interação e o desenvolvimento de estratégias que favorecam a aquisição de um raciocínio lógico com argumentação, base de toda a aprendizagem infantil, fundamental e acadêmica.

\section{As Contribuições da Ludicidade como um caminho para a aprendizagem}

O lúdico é um método que viabiliza o processo de ensino-aprendizagem com eficiência, entusiasmo, no qual as crianças aprendem de forma significativa, valoriza as 
práticas pedagógicas em sala de aula e de contribui para a construção de conhecimentos que serão presentes nas vivências futuras e diárias dos alunos, promovendo também o processo de ensino-aprendizagem.

Santos (2011):

Brincar é "divertir-se infantilmente"; lúdico é "relativo a jogos, brinquedos e divertimentos"; portanto, ao realizar uma atividade lúdica, estamos brincando e aprendendo, com o desenvolvimento do ser, juntamente com a felicidade; são fenômenos que ficarão marcados na essência do alunado (SANTOS, 2011, p.32).

O Brincar é divertir-se, segundo o autor, a ludicidade está relacionada à vida, a alegria de viver. O importante é reconhecer que a brincadeira, não é uma manifestação natural da criança, mas sim, histórica e social. Isto significa que, por um lado a brincadeira enquanto manifestação infantil apenas se desenvolve quando a criança está inserida em contexto que possibilite este aprendizado, e também garantir que as crianças tenham acesso à cultura, espaços e tempo para o brincar, construir e alicerçar conhecimentos.

Para Lima (2008) deve-se considerar que as relações que a criança estabelece não acontecem de forma natural, e sim através do meio em que está inserida. As habilidades e capacidades humanas que as crianças desenvolvem ao longo da vida não são hereditárias.

Contudo, no contexto escolar os educadores não conferem a devida importância ao aspecto lúdico a ser desenvolvido na e para a criança. Ao invés de valorizarem esta manifestação, despendem maior tempo da rotina institucional, para atividades voltadas ao aprendizado de conteúdos de cunho escolarizante (LIMA, 2008; SILVA, 2012).

A brincadeira amplia as habilidades motoras, cognitivas e sociais das crianças, a aprendizagem proporcionada pelas atividades lúdicas são aspectos que devem ser levados em conta como complementar ao da sala de aula, ambas igualmente necessárias no processo de desenvolvimento global das crianças na Educação Infantil.

As atividades lúdicas são necessárias para a interação da criança com o ambiente. Para Dias (2013, p.7) “Através do lúdico a criança começa a desenvolver sua capacidade de imaginação, abstração e aplicar ações relacionadas ao mundo real e ao fantástico". As atividades lúdicas são necessárias para a interação da criança com o ambiente.

Porém, muitas dúvidas permeiam educadores, pais e instituições de ensino no que se refere a importância das atividades lúdicas na aprendizagem infantil, pois essas atividades 
ainda não são vistas como recursos pedagógicos imprescindíveis para o desenvolvimento da criança. Ao contrário, são vistas como ocupação aleatória do tempo livre ou modo de passar o tempo, uma maneira para as crianças descarregarem as energias e meio para aprendizagem de conteúdo (LIMA, 2008).

Discutir a importância das atividades lúdicas no desenvolvimento infantil, remete os benefícios de se trabalhar com as mesmas para a ampliação da capacidade motora, cognitiva e social das crianças. Ao elaborar esta pesquisa clarifica-se a discussão entre dos educadores, escolas e pais de alunos, o que falta a ludicidade na Educação Infantil?

Será por meio das brincadeiras que as crianças irão se apropriar da cultura humana, ou seja, se desenvolver. (LIMA, 2008; SILVA, 2015)

Contudo, os autores que pesquisam a temática explicam que, muitos professores dizem não ter, em seu processo de formação inicial, suporte teórico/prático necessário para introduzir essas atividades nas instituições que atuam. Além disso, as instituições não estão aptas para auxiliar nos quesitos de disponibilização de material, espaço e tempo na grade curricular para que se transcorra o desenvolvimento das atividades lúdicas. Ainda assim, quando poucos educadores tentam inserir tais atividades no seu plano de aula, tem receio de desenvolvê-las, pois pais e diretores podem questionar o seu trabalho. (SILVA; LIMA, 2015)

O educador deve promover um ambiente de interação para que as crianças troquem informações ao passo que o seu conhecimento de mundo começa a ser conceitualizado. Como mediador destas relações, amplia, então, este conhecimento trazendo e apresentando novos temas e conteúdos para que as crianças se apropriem da cultura humana.

A relação que era interpessoal reflete no processo de desenvolvimento intrapessoal. Por esta razão, as brincadeiras constituem como proposta educativa na Educação Infantil por incidir diretamente no desenvolvimento das crianças. Será por meio das brincadeiras que as crianças irão se apropriar da cultura humana, ou seja, se desenvolver (LIMA, 2008; SILVA, 2015).

Quanto mais enriquecedora for a relação interpessoal, melhor será estruturada a relação intrapessoal, ou seja, a qualidade da relação intrapessoal depende da qualidade que ocorre a relação interpessoal.

É a partir desta ideia que Lima (2008, p. 96) destaca o papel das instituições de educação como local privilegiado de mediação da cultura humana, enfatiza "O sistema educacional, em todas as suas modalidades, exerce um papel essencial para que a geração 
mais nova se aproprie da produção cultural, desenvolva as suas faculdades humanas e possa se inserir e atuar no seu contexto sócio histórico".

A infância é uma das fases na qual a criança está começando a desenvolver, portanto, torna-se importante proporcionar-lhes momentos prazerosos e educativos, envolvendo brincadeiras, jogos e brinquedos, fazendo com que sinta-se livre para que use a imaginação. Todavia, muitos educadores não estão preparados ou não dão a devida importância para o desenvolvimento das atividades lúdicas e o ambiente escolar.

Com base na literatura pesquisada percebe-se que as atividades lúdicas são de extrema importância para o desenvolvimento global das crianças, porém, para que haja um bom desempenho das atividades lúdicas no âmbito educacional, o ambiente escolar, pais e professores devem agir em conjunto, ou seja, todos que participam de modo direto e indireto no processo de desenvolvimento das crianças, todos precisam entender que brincar é importante.

As atividades lúdicas auxilia no desenvolvimento da imaginação, do raciocínio, da criatividade, na construção do sistema de representação, visando o desenvolvimento dos aspectos motor, cognitivo, físico e psicológicos das crianças. Esta é uma necessidade de todo ser humano, podendo ser uma diversão, mas também um instrumento muito eficaz no aprendizado e desenvolvimento infantil como um todo.

Para Silva (2015):

A brincadeira, por si só, incita à convivência entre os pares, pois, durante as brincadeiras, as crianças observam, escutam, utilizam a linguagem oral, trocam informações, contemplam diferentes pontos de vista e diferentes modos de vida enriquecendo suas referências; desenvolve o pensamento e a memória ao solucionar problemas surgidos no grupo. (SILVA, 2015, p. 127).

A brincadeira quando utilizada como recurso pedagógico não é visto como atividade que influencia de forma significativa na aprendizagem e, infelizmente, é usado apenas para preencher o tempo e/ou para viabilizar aprendizagens de conteúdos escolares, por exemplo o cálculo, a leitura e a escrita.

É Preciso reconhecer que a brincadeira possibilita à criança vivências e experiências que contribuem com o seu desenvolvimento. Durante a brincadeira, a criança conhece e 
divide regras sociais, comportamentos, ideias e leituras sobre a sociedade (LIMA, 2008; SILVA, 2012).

O brincar é uma atividade constante na vida de toda criança, algo que lhe é natural e muito importante para o seu desenvolvimento. As brincadeiras, para a criança, constituem atividades primárias que trazem grandes benefícios do ponto de vista físico, intelectual e social e a maneira como a mesma brinca reflete sua forma de pensar e agir.

A brincadeira lúdica vem ampliando sua importância, deixando de ser um simples divertimento e tornando-se uma ponte entre a infância e a vida adulta.

O grande desafio para o educador no contexto atual é ensinar os conteúdos propostos pelos programas curriculares de uma forma criativa, significativa, contextualizada e prazerosa para os aprendizes. Achamos que nas escolas de formação para o magistério, nos cursos de Pedagogia os alunos deveriam ser estimulados a analisar as atividades lúdicas, a criticá-los, envolvendo-se eles mesmos nessas atividades. Isto porque o educador devis vivenciar a atividade de ensino, ao considerar nos planos afetivos e cognitivos, os objetivos, a capacidade do aluno, os elementos culturais e os instrumentos capazes de colocar o pensamento da criança em ação.

Vygotsky (1984) chama de zona de desenvolvimento proximal:

[....] zona de desenvolvimento proximal é a distância entre o nível de desenvolvimento real, que se costuma determinar através da solução independente de problemas, e o nível de desenvolvimento potencial, determinado através da solução de problemas sob a orientação de um adulto ou em colaboração com companheiros mais capazes. (VYGOTSKY, 1984 p.97)

Dentre as competências a serem construídas e desenvolvidas pelo docente encontra-se a capacidade de desenvolver uma relação professor-aluno que propicia ao processo ensinoaprendizagem. Se o ato de brincar é espontâneo, qual será a função do educador durante essa atividade?

A função do professor durante os jogos e brincadeiras deve ser o de provocar e desafiar a participação coletiva na busca de encaminhamentos e resolução dos problemas, pois é através dos jogos que se desperta e incentiva-se a criança para o espírito de companheirismo e de cooperação. 
Segundo Vygotsky (1991), antes dos três anos, a criança ainda não desenvolveu o pensamento abstrato e por isso age de acordo com a estimulação imediata dos objetos. Embora uma criança esteja brincando em uma situação de faz-de-conta, a brincadeira deve seguir regras. Da mesma forma de uma situação imaginária, como em uma definição de regras específicas, o brinquedo propicia, na criança.

Santos (1997) defende a não existência de uma sequência rígida de desenvolvimento entre os tipos de jogos da criança e o fato de que o surgimento de um tipo de jogo não exclui o aparecimento de outro, classificando a evolução do ato de brincar da seguinte maneira:

- Jogos funcionais: são observados nos bebês, caracterizados pelos movimentos que a criança realiza com o próprio corpo e posteriormente com os objetos;

- Jogos de ficção: caracterizados pelas situações de faz-de-conta, auxiliando no desenvolvimento do pensamento abstrato e também na compreensão dos papéis e do relacionamento entre as pessoas, além de servirem de base para o surgimento dos jogos de regras, nos quais a criança aprende a importância da dinâmica em grupo.

- Jogos de aquisição: caracterizam-se pelo comportamento de observação que a criança apresenta frente a uma situação, objeto, ou algo que esteja sendo explicado a ela, quando permanece quieta e encontra-se num processo intenso de trabalhar as questões dos significados para compreender o que está ocorrendo.

- Jogos de fabricação: onde a criança explora determinada situação ou objeto com o objetivo de compreendê-los.

Observa-se, dessa maneira, que muitos autores afirmam que o ato de brincar para a criança é tão sério quanto o trabalho é para uma pessoa adulta, pois através da brincadeira que a criança estimula sua imaginação e de compreende as relações entre as pessoas, ou seja, o ato de brincar configura-se como fator decisivo no processo de desenvolvimento e estruturação da criança.

O Referencial Curricular Nacional para a Educação Infantil - RCNEI (2006) resgata a importância do brincar no cotidiano dos Centros de Educação Infantil. Essa foi uma relevante contribuição para a Educação Infantil. No entanto, esse movimento não é instantâneo nem está garantido pelo fato de existir espaços para discursões, reflexões e leituras críticas sobre o assunto.

720 Id on Line Rev. Mult. Psic. V.13, N. 46 p. 714-728, 2019 - ISSN 1981-1179 Edição eletrônica em http://idonline.emnuvens.com.br/id 
É necessário coragem para assumir que o trabalho é primordial no trabalho com as crianças de 0 a 6 anos. É imprescindível, também, que essa postura seja abraçada por toda a equipe escolar (do diretor aos coordenadores; dos auxiliares aos funcionários que prestam serviços na escola), não somente pelo professor de classe. (FRIEDMANN, 2012)

Em diversos estados, verifica-se um intenso empenho e responsabilidade, sobretudo da direção dos Centros de Educação Infantil, em formar suas equipes, sem se esquecer do momento e da individualidade de cada educador. No contato e na conversa com algumas educadoras, é possível sentir a coerência e a consciência no trabalho desenvolvido na sala de aula com relação ao brincar.

Em diversos Centros de Educação Infantil, há um "reflexo do que pode ser chamado de "revolução" em ação - espaços em via de transformação, salas, materiais; a elaboração de projetos; o entusiasmo da direção das escolas -, ilustração clara da evolução que a proposta do Referencial Nacional para a Educação infantil levou para educadores, técnicos, crianças, pais e para a comunidade. (FRIEDMANN, 2012, p.151)

Há ainda um bom caminho a ser percorrido no sentido de internalizar os conceitos apresentados no RCNEI com relação ao brincar, para, efetivamente, poderem ser não somente transmitidos, mas assumido pelos educadores em sua pratica com as crianças. Este é um momento extremamente importante, ao assumirmos novos paradigmas e patamares; e, apesar de nos depararmos com grupos de educadores de nível de consciência e atuações excelentes, os encontros de formação (cursos, reciclagens, workshops estimulados pelos Centros de Educação Infantil) são uma entre várias estratégias necessárias para que o brincar se torne uma prática consciente.

É interessante relatar problemas, necessidades, interesses e potenciais das crianças com relação ao brincar, levantados por alguns grupos de educadores que participam do processo de formação sobre o brincar nos Parâmetros em Ação. É importante apontar que muitos dos problemas aqui alcançados têm sido criadas. Porém, embora tenha se passado mais de uma década desde esse levantamento, constata-se que em muitos Centros de Educação Infantil e creches muitas dessas questões perduram:

Problemas de: Equilíbrio; Concentração e atenção; Aceitação de regas; Discriminação social e étnica; Falta de cooperação; Agressividade; Inadequação especialistas; Falta de materiais para proporcionar o brincar; Inadequação de mobiliário; Falta de profissionais de Educação Física.

\section{Id on Line Rev. Mult. Psic. V.13, N. 46 p. 714-728, 2019 - ISSN 1981-1179} Edição eletrônica em http://idonline.emnuvens.com.br/id 
Necessidade de: Movimentar-se; Socializar-se; Brincar de faz de conta; Desenvolver habilidades; Trabalhar noções de limites e regras; Trabalhar noções abstratas, como a liberdade, a socialização, a cooperação; Trabalhar a higiene; Trabalhar atividades lúdicas, e recreação e musicais. Interesses por: Pintura; Jogo; TV, vídeo, videogames; Jogos de imitações; Jogos de competição; Brincadeiras livres; Histórias; Fantoches; Ler e escrever; Brincar; Música, filmes e passeios. Potenciais para: Representar; Criar livremente utilizandose de diversas formas expressivas; Criar jogos e brincadeiras; Criar novos significados para as coisas (jogo simbólico, desenhos).

As preocupações levantadas com relação às crianças e sugestões para trabalhar tais projetos e partir de propostas de atividades lúdicas estão relacionadas a seguir.

- É importante que os educadores conheçam os potenciais do brincar e a necessidade de o próprio adulto aprender a brincar.

- A respeito da sexualidade, casos específicos (masturbação, jogos sexuais etc.) podem ser trabalhados com atividades que canalizem energia, como modelagem, expressão corporal, espelho etc. de todo modo, o educador precisa ter mais orientações sobre sexualidade inclusive sua própria, para poder, assim, lidar melhor com um tema tão difícil de ser trabalhado.

- Atividades que façam as crianças se aceitarem, como música, brincadeiras, exercícios com toques, narrações de histórias e contos, escolha de ajudante do dia, são ideias para trabalhar a baixa autoestima. É importante que o educador: faça elogios; não exponha as dificuldades da criança; valorize as produções de cada uma; estimule-as, quando discriminadas ou comparadas com outras; trabalhe valores, respeito, diferenças etc.

- Sobre conflitos/brigas que surgem na escola, é aconselhável resolvê-los no momento em que acontecem e promover discussões em grupo sobre limites, regras, entre outros assuntos.

- Situações de agressividade, em que as crianças brincam com armas de brinquedo (revolver, espada etc.), podem ser encaminhadas a partir de um diagnóstico inicial, em que o educador conversa com os pais, trazendo-os como parceiros. Além disso, necessário desenvolver um trabalho informativo e de conscientização e também propor brincadeiras que atendam interesses e 
necessidades das crianças e as ajude a descarregar energia, como corrida, futebol etc. O mais importante, em todo caso, é que as crianças sejam ouvidas.

Para Snyders (1984) apud Wajkop (2012) a visão da criança que se criou neste contexto possibilitou a expansão do desejo de superioridade por parte do adulto, que mantinha sobre os pequenos um julgo inquestionável, que crescia à medida que estes iam sendo isolados do processo de produção.

Chama a atenção, nas visitas a algumas escolas, e a preocupação de envolver a comunidade e os pais nas propostas e projetos, tornando-os, assim, corresponsáveis pelo cuidado com o espaço físico e envolvendo-os com o ambiente escolar.

Outra particularidade diz respeito à proposta da criação em algumas escolas, de "espaços alternativos" - salas que servem para desenvolver atividades paralelas, sobretudo porque, na maioria das escolas as turmas são muito grandes (40 a 50 crianças). Esses espaços funcionam de seguinte maneira: enquanto metade do grupo desenvolvem trabalhos na sala de aula, o restante apropria-se do espaço alternativo, onde desenvolve atividades mais livres, como brinquedoteca, leitura, vídeos, música etc.

Sobre os objetivos das atividades lúdicas, Góes (2000) explica:

Os objetivos são explorados e manipulados conforme suas características físicas ou funcionais; motivação e percepção estão de certa forma, superpostas. No entanto, quando começa a construção do faz de conta, opera-se uma separação dos campos da percepção e da motivação, pois as ações são simuladas e uma coisa é usada para significar outra. O campo do significar outra. $\mathrm{O}$ campo do significado se impõe, de maneira que a criança passa a agir com os objetos não apenas em função do que percebe. (GÓES, 2000, p.1)

Existem propostas de implantar brinquedotecas em várias escolas, assim como de incentivo e valorização da cultura local, que aparece, em especial, nos brinquedos artesanais e nas brincadeiras tipicamente regionais.

Outros pontos levantados nesses encontros por alguns formadores:

- O brincar estaria deturpado, muitas vezes não se relacionando com o aprendizado e o desenvolvimento infantil;

- Há dúvidas quanto ao que são brincadeiras livres e brincadeiras dirigidas;

- Muitas vezes os educadores têm dificuldades e dúvidas sobre como observar ou ouvir sem interferir. 
De fato, há dúvidas entre formadores e professores com relação a conceitos básicos. Mas os professores precisam aceitar e confiar mais não somente nas propostas e estudos de teóricos e pesquisadores, como também em si próprios, nas suas percepções e valores, e nas necessidades, interesses e habilidades do grupo de crianças com o qual trabalham.

\section{O Plano Nacional pela Primeira Infância}

O Plano Nacional pela Primeira infância foi construído em um processo de ampla participação social no qual se envolveram organizações do governo e da sociedade civil, pesquisadores, especialistas, gestores públicos, movimentos e redes especializadas em diferentes áreas do desenvolvimento infantil e dos direitos da criança. Seu lançamento se deu em dezembro de 2010, sendo, em seguida, aprovado pelo Conanda (Conselho Nacional dos Direitos das Crianças e dos Adolescentes) e acolhido pela Secretaria dos Direitos Humanos, da Presidência da República, como uma grande contribuição para o país na área da primeira infância. Essa Secretaria, à qual compete coordenar as ações intersetoriais na área dos direitos da criança, assumiu o papel de coordenadora do plano.

Nesse Plano estão traçadas as diretrizes gerais e os objetivos e metas até 2002, que o Brasil deverá realizar em cada um dos direitos da criança afirmados pela Constituição Federal e pelo Estatuto da Criança e do Adolescente.

Considerando que todos os entes federados têm responsabilidades e competências constitucionais e legais no atendimento à criança, apoio técnico e financeiro da União dos estados, Plano Nacional pela Primeira Infância propõe que os estados, o Distrito Federal e os municípios elaborem seus planos estaduais e municipais pela criança, segundo as diretrizes, objetivos e metas do Plano Nacional.

Friedmann (2012) esclarece:

A ideia é ter uma imensa rede de compromissos, firmados em planos que se articulem e complementem, e que, pelo menos nos municípios, sejam transformados em leis. A Rede Nacional Primeira Infância, responsável pelo Plano, espera que, dessa forma, a criança seja efetivamente sujeito de atenção em todos e cada um de seus direitos. (FRIEDMANN, 2012, p. 155)

O documento aponta para alguns avanços recentes, tais como: 
- Sistema de Garantia dos Direitos das Crianças e Adolescentes;

- Políticas de atendimento da criança e do adolescente;

- Políticas, planos e programas setoriais específicos para a primeira infância ou que a incluem em seu escopo;

- Investimento crescente de recursos financeiros na infância e adolescência; os fundos da criança e do adolescente;

- Rede de Monitoramento Amiga da Criança;

- Observatório Nacional dos Direitos da Criança e do Adolescente;

- Pacto Nacional "Um mundo para a criança e o adolescente do Semiárido".

Vale destacar as ações finalísticas do plano, dentre elas: Saúde das crianças; Educação Infantil; Família e comunidade da criança; Assistência social às crianças e suas famílias; Atenção à criança em estado de vulnerabilidade; Acolhimento institucional; Família acolhedora, adoção; Direito de brincar e o brincar de todas as crianças; A criança e o espaço a cidade e o meio ambiente; A questão da diversidade (crianças negras, quilombolas e indígenas); Enfrentamento das violências contra as crianças; Documento de cidadania a todas as crianças; Proteção das crianças contra a pressão consumista; Controle da exposição precoce das crianças aos meios de comunicação.

Brenelli (2014) faz referência a Kamii (2009) ao relatar sobre a atividade como componente metodológico, considerando os jogos de regras com princípios Piagetanos importantes ferramentas para favorecer o pensamento e geral, desenvolver a cooperação e a autonomia. As autoras enfatizam que as crianças aprendem por meio dos jogos e o professor pode intervir para potencializar essa aprendizagem.

A mais recente contribuição elaborada pela Rede Nacional Primeira Infância é o Guia para Elaboração de Planos Municipais pela Primeira infância, com o intuito de que as crianças de 0 a 6 anos ganhem visibilidade, sejam ouvidas e recebam atenção e os cuidados necessários ao seu desenvolvimento e tenham seus direitos respeitados, por meio da sensibilização e conscientização de municípios, sociedade civil organizada, famílias, empresários e representantes de comunidades.

Para Malaguzzi (1999),

Outro fato, ainda, que em minha opinião explica o ataque sobre nossas escolas, foi o rápido crescimento da influência cultural de nossa experiência. 
Nosso trabalho, os seminários, os encontros e as publicações haviam contribuído para um reconhecimento nacional de nossas escolas operadas pela municipalidade. (MALAGUZZI, 1999, p.65).

Vale destacar que o Plano Nacional pela Primeira Infância tem um olhar sensível e prospectivo para o direito de a criança brincar. Em diferentes capítulos chama a atenção para a crescente redução de espaços de jogos e brincadeiras na infância em casa, na escola e na cidade.

E determina a instalação de diferentes equipamentos para o lazer e a brincadeira na primeira infância no espaço urbano, como parques, praças, jardins e brinquedotecas fixas e itinerantes - que cheguem à zona rural - e oficinas do brincar, como também brinquedotecas em locais em que as crianças passam horas do dia, como hospitais infantis, aeroportos etc.

O Plano tem um capítulo específico sobre esse tema: "Do Direito de Brincar ao Brincar de todas as Crianças", cuja leitura é recomendável a todos os educadores de Educação Infantil.

\section{Considerações Finais}

Alguma resistência por parte muitos profissionais, levam a crer que os mesmos ainda não compreendem como deve ocorrer o processo de Inclusão de brincadeiras e jogos na sala de aula, no ambiente escolar, e muitas vezes, deixam as crianças sentadas, ou envolvidas em outras atividades. Há um certo paradigma de que no momento da brincadeira, a criança não está fazendo nada, está só brincando, sem que se dê conta que é nesse momento que a criança constrói, constitui-se.

Todos os profissionais das instituições escolares de educação infantil, escola, hospitais e outros, devem estar envolvidos, e com o necessário conhecimento e habilidade para atender às crianças ante os novos desafios. A ludicidade deve existir em todos os espaços sociais, promovendo alegria e desenvolvimento.

O lúdico se faz necessário, e para que ocorra com maior intensidade, é preciso investir em políticas públicas que promovam a capacitação de profissionais, envolvendo a família e os demais segmentos sociais, para que juntos sintam a importância destas atividades prazerosas. 
Espera-se que a importância da ludicidade seja cada vez mais reconhecida, valorizada e implementada, tornando a escola um espaço de criatividade e sonhos, onde cada criança que organize seu "mundo" através das brincadeiras.

\section{Referências}

BRASIL. Ministério da Educação e do Desporto. Secretaria da Educação Fundamental. Referencial Curricular Nacional para a Educação Infantil - volumes 1, 2 e 3. Brasília. MEC/SEF. 1998. 1996a. v.1.

Referencial Curricular Nacional para a Educação Infantil. Brasília: MEC/SEF,

BRENELLI, Roseli Palermo. O jogo como espaço para pensar: a construção de noções lógicas e aritméticas. Campinas: Papirus. 2015.

DIAS, E. A importância do lúdico no processo de ensino-aprendizagem na Educação Infantil. Revista Educação e Linguagem - Artigos. Vol. 7, n 1, 2013. ISSN 1984 - 3437.

FRIEDMANN, Adriana. O brincar na educação infantil: observação, Adequação e inclusão / - 1. Ed. São Paulo. Moderna. 2012.

GÓES, Maria Cecília Rafael de. O jogo imaginário na Infância: a linguagem e a criação de personagens. In: Reunião anual da Amped, 23. 2000. Caxambu. Anais...

LIMA, Bruna Alessandra Silva. O brincar na educação infantil: o lúdico como estratégia educativa. 2013. 76 f. Trabalho de Conclusão de Curso (Graduação em Pedagogia) Faculdade de Educação da Universidade de Brasília.

LIMA, José Milton de. A importância do jogo no desenvolvimento da criança na perspectiva da Teoria Histórico Cultural. O Jogo como Recurso Pedagógico no contexto Educacional. Editora Cultura Acadêmica. São Paulo. 2008.

MALAGUZZI, Loris. História, ideias e filosofia básica. In: EDWARDS, Carolyn;

MALUF, Ângela Cristina Munhoz, Brincar prazer e aprendizado. Petrópolis, RJ:Vozes, 2003.

SANTOS, TR, Pfeifer LI, Silva DBR, Panuncio-Pinto MP. Avaliação do comportamento lúdico de crianças com paralisia cerebral. Arquivos Brasileiros de Paralisia Cerebral. 2011.

SILVA, José Ricardo. A brincadeira na educação infantil: uma experiência de pesquisa e intervenção. Dissertação de mestrado, Unesp, Presidente Prudente, 2012. 
.; LIMA, José Milton de. A brincadeira na educação infantil: uma experiência de pesquisa e intervenção. Revista Teias. p. 176 - 191. Vol 16, n ${ }^{\circ}$ 41. 2015.

SNYDERS, Georges. A escola pode ensinar as alegrias da música? São Paulo: Cortez, 1992.

VIGOTSKI, L. S. A construção do pensamento e da linguagem. São Paulo. Martins Fontes. 1991.

A Formação social da mente. São Paulo. Martins Fontes. 1984.

A formação social da mente. São Paulo: Martins Fontes, 1991.

\section{Como citar este artigo (Formato ABNT):}

SANTOS, Josilene de Resende; MIGUEL, Joelson Rodrigues. O Lúdico na Educação Infantil . Id on Line Rev.Mult. Psic., 2019, vol.13, n.46, p. 714-728. ISSN: 1981-1179.

Recebido: 18/07/2019;

Aceito: 20/07/2019. 